25. Лыгин С.А., Ваниева А.С. Оценка загрязнения воздуха методом лихеноиндикации // Естественные и математические науки в современном мире. 2014. № 18. C. $187-191$.

26. Анищенко Л.Н., Сковородникова Н.А., Борздыко Е.В. Химическая лихеноиндикация как основа биомониторинга воздуха в антропогенных экосистемах // Фундаментальные исследования. 2015. № 2-10. C. $2144-2148$.

27. Jovan S., McCune B. Air-quality bioindication in the greater Central Valley of California, with epiphytic macrolichen communities // Ecological Applications. 2005. № 15. Р. 1712-1726.

28. Мандельброт Б. Фрактальная геометрия природы. М.: Ижевский институт компьютерных исследований, 2002. 856 с.

29. Weibel E.R. Design of biological organisms and fractal geometry // Fractal in biology and medicine. Basel: Birkhäuser, 1994. P. 68-85.

30. Смирнов Б.М. Физика фрактальных кластеров. М.: Наука, 1991. 134 с.

31. Федер Е. Фракталы. М.: Мир, 1991. 260 с.

32. Гелашвили Д.Б., Иудин Д.И., Р Розенберг Г.С., Якимов В.Н., Солнцев Л.А. Фракталы и мультифрак- талы в биоэкологи. Н. Новгород: Изд-во Нижегород. госун-та, 2013. $370 \mathrm{c}$.

33. Гелашвили Д.Б., Иудин Д.И., Якимов В.Н., Солнцев Л.А., Снегирева М.С., Варичев А.Н., Розенберг Г.С. Фрактальные аспекты популяционной экологии // Вестник Удмуртского университета. Серия Биология. Науки о Земле. 2009. № 6-1. С. 15-22.

34. Молчатский С.Л. Фрактальная организация и самоорганизация нейронных структур мозга: монография. Самара: ПГСГА, 2015. 133 с.

35. Weibel E.R. Fractal geometry - a design principle for living organisms // Amer. J. Physiol. 1991. V. 261. № 6. P. 361-369.

36. Nonnenmacher F., Losa G.A., Weibel E.R. Fractals in biology and medicine: Basel: Birkhäuser Verlag, 1994. $421 \mathrm{p}$.

37. Исаева В.В., Каретин Ю.А., Чернышев А.В., Шкуратов Д.Ю. Фракталы и хаос в биологическом морфогенезе: монография. Владивосток: ИБМ ДВО PAH, 2004. $128 \mathrm{c}$.

38. Захаров В.М. Здоровье среды: методика оценки. М.: Центр экол. политики России, 2000. 68 с.

Статья публикуется при частичной поддержкке гранта РФФИ № 16-44-630414 p_a.

\title{
APPLICATION OF FRACTAL ANALYSIS FOR BIOINDICATION EVALUATION OF THE ENVIRONMENTAL ASSESSMENT
}

(C) 2016

S.L. Molchatsky, candidate of physical and mathematical sciences, associate professor of Chemistry, Geography and Methods of Teaching Department

I.V. Kazantsev, candidate of biological sciences, dean of Faculty of Natural Sciences and Geography, associate professor of Chemistry, Geography and Methods of Teaching Department

T.B. Matveeva, candidate of biological sciences,

associate professor of Biology, Ecology and Methods of Teaching Department

Samara State University of Social Sciences and Education, Samara (Russia)

\begin{abstract}
The paper analyzes the currently existing methods of bioindication studies of the environment pollution as well as studies their characteristics and applications. Particular attention from this group of methods is given to lichen indication and assessing the degree of fluctuating asymmetry of the leaf and its irregularity, because they are based on a study of the geometric characteristics of biological samples by means of mathematical processing using special software. It proves the possibility and prospects of application of the measuring method of fractal dimension for the qualitative and quantitative assessment of environmental pollution. Presented data show that the inclusion of the fractal nature of biological systems allows discovering and exploring a completely new range of phenomena in biology. The coincident of this method is provided with the goals and objectives by the appropriate mathematical apparatus. Within the framework of this approach it is possible to design and use new advanced monitoring techniques. In the final part of the paper a new concept of bioindication, which is based on a synthesis of both classical and innovative approaches to the study and assessment of environmental quality in the conditions of technogenic pollution, is proposed.

Keywords: anthropogenic pollution; bioindication; biological indicators; fluctuating asymmetry; leaf; woody plants; lichen indication; lichen; anthropogenic impact; pollutants; pollutants; fractal dimension; fractal analysis; fractal clusters.
\end{abstract}

УДК 58.02

\section{СУКЦЕССИЯ И ОСОБЕННОСТИ РАСПРОСТРАНЕНИЯ РАСТИТЕЛЬНЫХ АССОЦИАЦИЙ В ПОЛОСЕ ОТВОДА ЖЕЛЕЗНЫХ ДОРОГ}

(C) 2016

Н.А. Никитин, аспирант кафедры биологии, экологии и методики обучения

B.В. Соловьева, доктор биологических наук, профессор кафедры биологии, экологии и методики обучения Самарский государственный соииально-педагогический университет, Самара (Россия)

Аннотация. Полоса отвода представляет собой специфический антропогенный ландшафт, в котором протекающие процессы изменяются в своей направленности и интенсивности. Эрозионные процессы, в частности водная эрозия почв, приводят не только к изменениям почвенного покрова, но и растительного, посредством изменения плодородия почв, насыщенности питательными веществами, а также путем изменения влагообмена, 
структуры и механического состава почв. Основные характеристики флоры претерпевают структурные, количественные и другие изменения. Изменяется и растительный покров, состав растительных ассоциаций, скорость и направленность сукцессии, от зарастания сорной и рудеральной растительностью до устойчивых древесно-кустарниковых сообществ. Проведено эколого-геоморфологическое зонирование, показавшее распространение наиболее эродированных почв в непосредственной близости от полотна. Выявлена закономерность, согласно которой в наиболее антропогенно-нарушенных местообитаниях произрастает разнотравно-злаковопырейная ассоциация, с уменьшением антропогенной нагрузки, преобладающей становится разнотравнолугово-злаковая ассоциация. Также выявлена фитоиндикаторная роль Eletrygia repens L., как показателя нарушенности местообитаний, увеличивающего свое обилие в местах с наибольшей антропогенной нагрузкой, выходя за пределы полосы отвода по осыпающимся бровкам оврагов, по обочинам пересекающих полотно дорог, проявляя способность к «растеканию» из места непосредственного формирования.

Ключевые слова: полоса отвода железных дорог; эколого-геоморфологическое зонирование; эрозия почв; сукцессия растительных ассоциаций; Eletrygia repens; растительные ассоциации; антропогенная трансформация растительности; растительный покров; рудеральная растительность; сорная растительность; фитоиндикаторы.

Полоса отвода железных дорог является своеобразным антропогенным ландшафтом, в котором изменяются основные характеристики флоры, почвеннорастительного покрова, а также геоморфологические характеристики, приводящие к изменению различных процессов (эрозионных, денудационных и др.). В настоящий момент полоса отвода достаточно полно изучена во флористическом отношении [1-13], проведены геоморфологические изыскания [14-15], однако с геоботанической точки зрения полоса отвода остается мало изученной территорией.

Растительность полосы отвода железных дорог отличается значительной степенью горизонтальной неоднородности. Наиболее детальное определение горизонтальной неоднородности было сформулировано академиком В.Н. Сукачёвым [16], разделявшим ее на два типа: первый тип - это неоднородность в пределах низших единиц растительности, второй - это пестрая мозаика небольших участков сообществ или их фрагментов. Они относятся к различным ассоциациям, встречаются при быстро меняющихся и при этом закономерно повторяющихся условиях существования. Дальнейшим развитием учения о неоднородности растительности стало учение о мозаичности растительного покрова, которое выражается в наличии растительных группировок, различающихся по одному или нескольким признакам, таким как состав, соотношение и обилие видов, а также сложение, динамика и другие.

Исходя из причин, вызывающих мозаичность, выделяют - экологическую, обусловленную неоднородностью среды обитания; фитогенную мозаичность развивающаяся под влиянием самой растительности; антропогенную мозаичность, возникающую под влиянием антропогенного фактора, а также зоогенная мозаика, возникшая под воздействием биогенных экологических факторов.

Полоса отвода рассматривалась нами с точки зрения антропогенной мозаичности, в виде постройки полотна и зоны отчуждения, стохастического заселения ее пионерными сообществами, с постепенным преобладанием фитогенных факторов, оказывающих влияние на сложение растительного покрова в последующее время. Однако, высокая степень гемеробии не позволяет пренебречь антропогенным фактором в развитии и сложении растительности полосы отвода.

Для более наглядного описания растительности применялся метод экологических профилей. Прилегающие фитоценозы рассматривались на уровне ме- зокомбинаций в понимании С.А. Грибовой и Т.И. Исаченко [17], которые считают мезокомбинациями закономерно повторяющееся чередование однородных сообществ или микрокомбинаций, связанное преимущественно с формами мезорельефа. Составные части мезокомбинаций могут быть как близки по своей экологии, так и значительно отстоять друг от друга, и иметь свой ряд развития. При этом отдельные компоненты мезокомбинаций все же взаимодействуют друг с другом на уровне обмена видами и создания фитоклимата.

Методика и материаль исследований. Геоботанические исследования проводились по методике, предложенной Ю.Н. Нешатаевым [18] и включали в себя геоботанические описания пробных площадей, выделение различных участков растительности, меняющихся в зависимости от физико-географических условий. Составлялись бланки геоботанических описаний, на основании анализа бланков формировали списки видов, зарегистрированных на ключевых участках, определялась ярусность, обилие по шестибальной шкале. Далее проводился эколого-флористический и фтоценотический анализ видов, с целью выявления принадлежности растений к тем или иным экологическим типам, а также выявление фитоценотической роли видов. После этого составлялась первичная сортировка описаний, которая в дальнейшем ранжировалась по определенным факторам среды (рельеф, богатство почвы, увлажненность, засоленность), определялись основные таксономические единицы от формаций до ассоциаций. Затем составлялся чистовой вариант списка и сводной таблицы растительных ассоциаций, с указанием видов растений и их обилия. Сделано графическое изображение экологических и сукцессионных связей выделенных ассоциаций. Завершением являлось составление списка ассоциаций, сводной таблицы и схем экологических и сукцессионных связей.

Также растительность изучалась методом экологических профилей. Они закладывались на территориях с различными орографическими характеристиками и различными условиями увлажнения, температурного режима и другими показателями.

Всего сделано 102 геоботанических описания растительных сообществ на пробных площадках размером $100 \mathrm{M}^{2}, 12$ геоморфологических описаний ключевых участков, собрано 850 гербарных листов. В мате- 
Никитин Н.А., Соловьева В.В.

риалы исследования вошли результаты изучения экологических условий 25 овражных систем в пределах полосы отвода железных дорог.

Исследования сукцессий растительных ассоциаций полосы отвода железных дорог проводилось в Волжском и Кинельском районах Самарской области. С помощью экологического профилирования были выявлены особенности распространения выделенных ассоциаций в пространстве, а вычисление геоморфологических характеристик местности и определение эродированности почв, позволило установить зависимость между ее величиной и произрастающими в данных условиях растительными ассоциациями.

Результаты исследований и их обсуждение. В ходе исследований было выделено 16 растительных ассоциаций. Определено, что при движении к полотну железной дороги происходит постепенный переход от естественного фитоценоза к рудеральному типу растительности. Исходя из полученных в ходе исследований данных, мы констатируем, что в условиях повышенной антропогенной нагрузки значительное распространение получают пырейники, а также ассоциации, где субдоминантом выступает Elytrigia repens L. По мере уменьшения антропогенной нагрузки растительный фон рудеральных сообществ сменятся ассоциациями, в сложении которых принимают участие луговые виды с участием пырея. Выявленная закономерность говорит о роли Elytrigia repens L. как фитоиндикатора нарушенных местообитаний. C уменьшением антропогенной нагрузки рудеральные растительные сообщества заменяются на луговые и древесно-кустарниковые фитоценозы. К последним относятся древостои с преобладанием Acer negundo L. и Ulmus pumila L.

Установление сукцессионных (временных) связей на основании сравнительного изучения сообществ, составляющих экологические и фитоценотические пространственные ряды, играет огромную роль в изучении природных смен растительного покрова. Этот метод ценен и удобен тем, что дает возможность в течение одного сезона подобрать серии фитоценозов, которые рассматриваются как стадии разного возраста, относящиеся к одному и тому же сукцессионному ряду, и, таким образом, наметить этап за этапом весь ход вторичной сукцессии.

Анализ фитоценотических рядов в течение 20082016 гг. показал, что продолжительность сукцессии от вторичного антропогенно-нарушенного состояния до разнотравно-злаково-пырейной ассоциации длится около трех лет. Следующая смена фитоценозов до лугово-злаково-разнотравной ассоциации длится 7-10 лет. Окончательное формирование древесно-кустарниковой растительности происходит в течение 10 лет. В случае с активным кленом американским сукцессия ускоряется. На основании этих данных составлена схема сукцессии растительности в пределах полосы отвода в зависимости от антропогенной нагрузки (рис. 1).

Из 16 растительных ассоциаций на всем протяжении исследованных участков в непосредственной близости от полотна произрастает ассоциация Elytrigieta-poosum heteroherbosum, которая создает своего рода переходную полосу от сорного типа расти- тельности к естественному фитоценозу, характерному тому или иному участку. Также стоит отметить распространение данной ассоциации по осыпающимся склонам оврагов и грунтовым дорогам, пересекающим полотно, что указывает на ее приуроченность к наиболее нарушенным местам обитания (рис. 2).

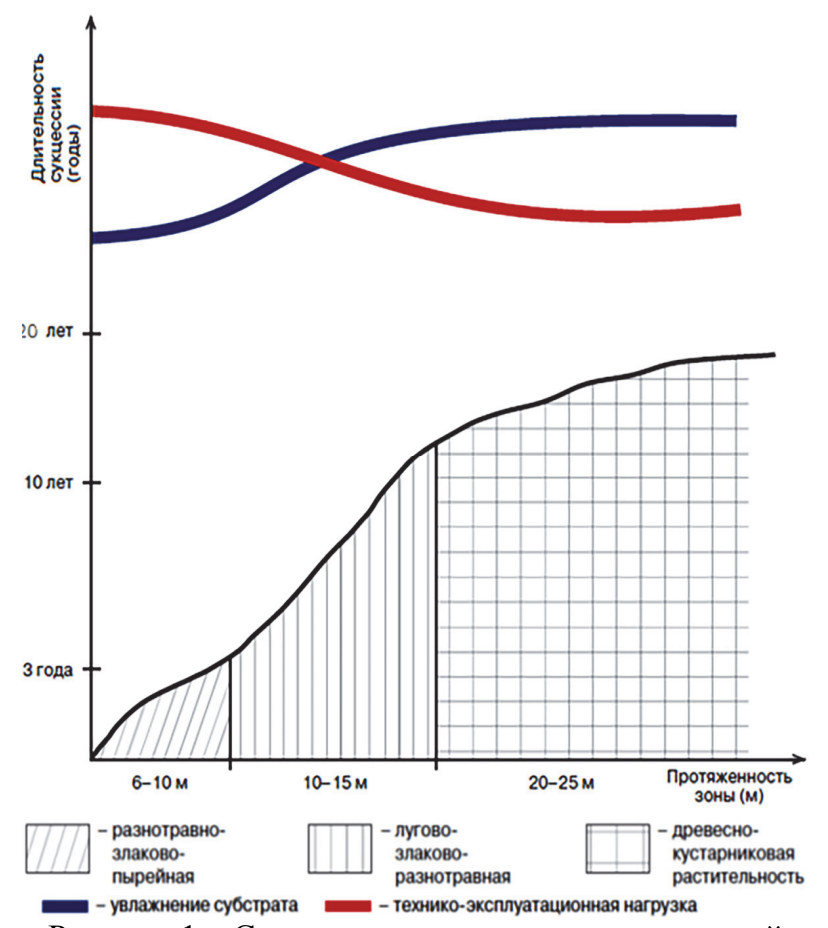

Рисунок 1 - Сукцессия растительных ассоциаций в условиях полосы отвода железных дорог

По результатам исследования составлена схема эколого-фитоценотической зависимости растительных сообществ. Так, на наиболее богатых и увлажненных почвах произрастает Phragmiteta-calamagrosum heteriherbosum, по мере снижения увлажнения и богатства почвы начинают преобладать ассоциации, где доминантами и субдоминантами выступает Elytrigia repens L. В условиях недостаточного увлажнения распространение получают Salvieta-leonuruosum heteroherbosum, Festuceta-achileosum heteroherbosum и Festuceta+elytrigiosum-achileosum heteroherbosum.

Подводя итог проведенным исследованиям можно сделать вывод о том, что почвы в пределах полосы отвода различаются по степени проявления водной эрозии - в непосредственной близости от полотна распространены сильносмытые почвы, при удалении степень развития водной эрозии уменьшается. В целом, для полосы отвода Куйбышевской железной дороги характерны высокие показатели крутизны и ширины склонов, а также расчлененности территории. Преобладает средняя (0,6-2,2 км²) пораженность почв овражной эрозией. Почвы полосы отвода являются эрозионноопасными, а также исходя из больших значений крутизны склонов (от 7-15²) - смытыми. Растительный покров полосы отвода представлен 16 растительными ассоциациями мозаичного характера. Основной фон составляют пырейники. Ведущую роль в сложении играют длиннокорневищные виды, способные к образованию сплошных задернованных участков, что приводит к уменьшению проявления водной эрозии. 


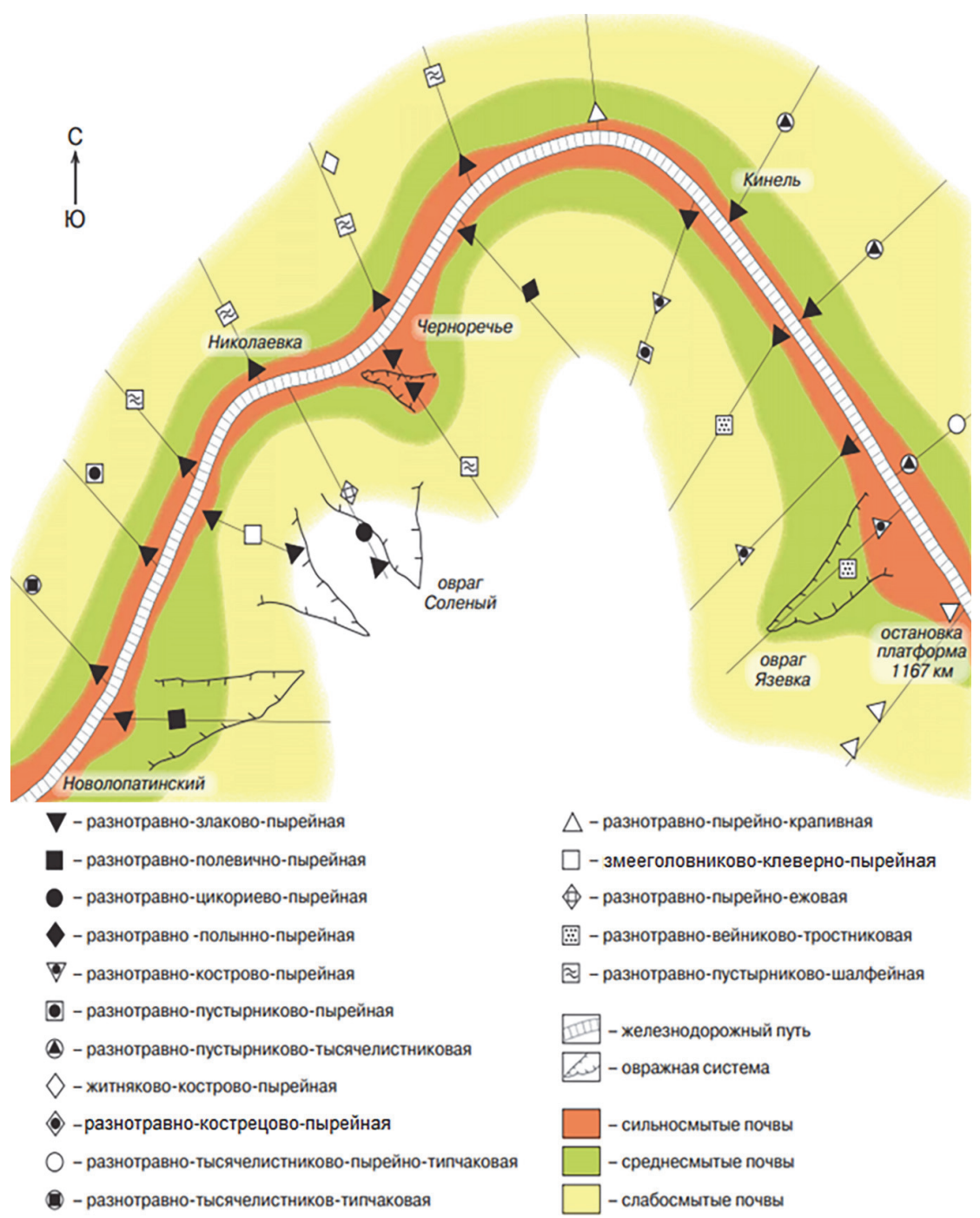

Рисунок 2 - Карта-схема эколого-геоморфологического и геоботанического зонирования исследованных участков полосы отвода Куйбышевской железной дороги

\section{СПИСОК ЛИТЕРАТУРЫ:}

1. Березуцкий М.А., Панин А.В., Шилова И.В. О новых и редких видах флоры города Саратова и его окрестностей // Бюллетень ботанического сада Сарат. ун-та. 2002. Вып. 1. С. 7-12.

2. Березуцкий М.А. Антропогенная трансформация флоры // Бот. журн. 1999. Т. 84, № 6. С. 8-19.

3. Березуцкий М.А., Панин А.В., Скворцова И.В. О находках редких и охраняемых растений на железнодорожных насыпях правобережья Саратовской области // Бюлл. бот. сада. Сарат. гос. ун-та. Вып. 2. Саратов, 2003. С. 5-7.

4. Борисова М.А. Дополнение к адвентивной флоре Костромской, Ярославской и Владимирской областей // Бюлл. МОИП, отд. Биология. 2007. Т. 112, вып. 6. С. 42-43.

5. Борисова М.А. Флора транспортных путей Ярославской области: дис. ... канд. биол. наук. Саранск. 2002. 272 c.

6. Голицын С.В. К вопросу об антропогенных миграциях растений // Советская ботаника. Т. ХІІІ, № 6. 1945. С. 21-27.

7. Голицын С.В. О «железнодорожных» растениях // Советская ботаника. № 5. 1947. С. 297-299.

8. Григорьевская А.Я. Флора города Воронежа. Воронеж: Изд-во Воронежск. гос. ун-та, 2000. 200 с.
9. Никитин Н.А. К вопросу об изучении флоры железных дорог Самарской области // Актуальные проблемы экологии и охраны окружающей среды: мат-лы VII Международ. науч.-практич. конф. Тольятти: Волж. унт. им. В.Н. Татищева, 2011. С. 126-130.

10. Пузырев А.Н. Дополнение к адвентивной флоpe Удмуртии // Бот. журн. 1985. Т. 70, № 2. С. 268-271.

11. Пузырев А.Н. Новые адвентивные виды сем. Brassicaceae в Удмуртии // Бот. журн. 1984. Т. 69, № 9. C. 1269-1270.

12. Пузырев А.Н. Новые и редкие адвентивные растения Удмуртии (по исследованиям 1981-1986 гг.) // Бот. журн. 1989. Т. 74, № 5. С. 761-765.

13. Пузырев А.Н. О новых и редких адвентивных видах семейства Роасеае в Удмуртии // Бот. журн. 1985. T. 70, № 1. С. 118-119.

14. Чигаркин А.В. Опыт применения ландшафтных исследований при проектировании новых железнодорожных трасс // Вестн. Моск. ун-та. Сер. География, 1962. № 3. С. 18-24.

15. Юровский Б.Л. Оценка рельефообразующих процессов в целях рационального природопользования при транспортном строительстве // Экзогенный морфогенез в различных типах природной среды: Тез. докл. Всес. конф. М., 1990. С. 184-185. 
16. Сукачев В.Н. Руководство к исследованию типов лесов // Госиздат с.-х. и колхозн-кооперат. лит. М.-Л., 1931.

17. Грибова С.А., Исаченко Т.И. Картирование растительности в съемочных масштабах // Полевая геоботаника. IV. 1972. C. 95-136.
18. Нешатаев Ю.Н. Методика обработки геоботанических описаний в учебной практике кафедры геоботаники Ленинградского университета // Методы выделения растительных ассоциаций. Л.: Издательство «Наука» Лениградское отделение, 1971. С. 23-37.

\section{SUCCESSION AND FEATURES DISTRIBUTION PLANT ASSOCIATIONS IN ROW OF RAILWAYS}

(C) 2016

N.A. Nikitin, postgraduate student of Biology, Ecology and Methods of Teaching Department

V.V. Solovieva, doctor of biological sciences, professor of Biology, Ecology and Methods of Teaching Department Samara State University of Social Sciences and Education, Samara (Russia)

Abstract. ROW is a specific man-made landscape, in which the processes of change occur in its direction and intensity. Erosion processes, in particular the processes of water erosion of soil, lead not only to changes in the soil, but the plant through changes in soil fertility, nutrient richness, and by changing moisture exchange, structure and texture of soils. The main characteristics of flora undergo structural, quantitative and other changes. Vegetation characteristics, composition of plant associations, the speed and direction of succession, from the initial stage of overgrown weeds and ruderal vegetation to sustainable tree and shrub communities also modify. An ecological and geomorphological zoning shows the prevalence of the most eroded soils in the vicinity of the web. The regularity according to which in most habitats anthropogenic disturbed grow motley-grass-wheatgrass association with a reduction of anthropogenic load becomes dominant forb meadow-grass association. The role of indication of Eletrygia repens L. was also identified as an indicator of habitat disturbance.

Keywords: ROW railways; ecological and geomorphological zoning; soil erosion; succession of plant associations; Eletrygia repens L.; plant associations; anthropogenic transformation of vegetation; vegetation; ruderal vegetation; weeds; phytoindicator.

УДК 581.55:502.72(477.60)

\section{СИНФИТОСОЗОЛОГИЧЕСКАЯ ОЦЕНКА РАСТИТЕЛЬНОСТИ ПАСТБИЩНЫХ ЭКОСИСТЕМ ЮГО-ВОСТОКА УКРАИНЫ} (C) 2016

В.М. Остапко, доктор биологических наук, профессор,

заведующий отделом природной флоры и заповедного дела, заместитель директора по научной работе Донеикий ботанический сад, Донеик (Донеикая Народная Республика)

О.М. Шевчук, доктор биологических наук, заведующий лабораторией ароматических и лекарственных растений Никитский ботанический сад - Национальный научный центр РАН, Ялта, п.г.т. Никита (Россия)

С.А. Приходько, кандидат биологических наук, заведующий отделом фитоэкологии, директор Донеикий ботанический сад, Донеик (Донеикая Народная Республика)

Аннотация. В составе растительности пастбищных степных экосистем юго-востока Украины выявлено 62 раритетные формации (79\% общего их количества) с 338 (52\%) раритетными ассоциациями доминантной классификации. В Зелёную книгу Украины включены 18 формаций с 79 ассоциациями (соответственно - 54\% и $67 \%$ этих синтаксонов растительности региона), остальные формации и ассоциации являются регионально редкими. Приводится перечень раритетных формаций и входящих в них ассоциаций растительности с распределением по типам пастбищных степных экосистем. Самым высоким синтаксономическим разнообразием характеризуются овражно-балочные степные экосистемы, сформировавшиеся на смытых чернозёмах, подстилаемых лёссами (750 ассоциаций из 81 формации), наименьшим - растительность надпойменно-террасовых степей на песках (140 ассоциаций из 24 формаций). Наибольшее количество регионально редких ассоциаций ценотически приуроченны к меловым обнажениям: здесь отмечено 49 ассоциаций из 16 формаций. Большое количество ассоциаций являются стенотопными. Полученные результаты позволяют говорить о высокой синфитосозологической ценности растительности пастбищных экосистем на юго-востоке Украины, что очень важно для сохранения биоразнообразия степного биома. Это следует учитывать при обосновании объектов территориальной охраны биоты, а также - при разработке режимов охраны и расчёте пастбищных нагрузок для конкретных участков.

Ключевые слова: синфитосозология; раритетная формация; раритетная ассоциация; степная экосистема; пастбищная экосистема; юго-восток Украины; Зелёная книга; растительность; синтаксономическое разнообразие; фитоценотическое разнообразие; водораздельная экосистема; овражно-балочная экосистема; надпойменно-террасовая экосистема. 